\title{
Idiopathic Scrotal Calcinosis
}

\author{
Madhura Milind Killedar $^{1}$ - Aslam A. Shivani ${ }^{1}$ • Usha Shinde ${ }^{1}$
}

Received: 9 March 2010 / Accepted: 9 March 2010 /Published online: 19 March 2016

(C) Association of Surgeons of India 2016

\begin{abstract}
Idiopathic scrotal calcinosis (ISC) is a rare benign condition which presents with multiple, asymptomatic, and painless nodules on the scrotal skin wall. The lesions have been attributed as sebaceous cysts, calcified steatocystoma, fibroma, atheroma, and xanthoma. Shapiro et al. reviewed the histologic data and found no evidence of an epithelial lining, residual cysts, and lipid or organisms, and concluded that the calcification was idiopathic introducing the term "idiopathic scrotal calcinosis." We have studied four cases of idiopathic scrotal calcinosis, one of which had scrotal calcinosis involving the whole of the scrotum. He presented with painless multiple nodules over the scrotum. He was subjected for surgery with SOS skin grafting, but as the scrotal skin is so lax, primary closure is easily possible. In all our four cases, primary closure was easily possible.
\end{abstract}

Keywords Calcinosis $\cdot$ Inclusion cyst $\cdot$ Scrotal swellings

\section{Case History}

A 40-year-old male came in surgery OPD for multiple painless nodules involving the whole of the scrotum (Fig. 1). All routine investigations including HIV and VDRL were done which were normal. He was posted for in toto excision with skin grafting, but surprisingly, primary closure was possible

Madhura Milind Killedar mdhurakilledar@gmail.com

1 Bharati Vidyapeeth Deemed University Medical College and Hospital, Sangli, India and his postoperative recovery was very good (Fig. 2). The specimen was sent for histopathology which was suggestive of calcinosis of the scrotum (Fig. 3).

\section{Discussion}

Lewinski in 1883 first described this condition. Idiopathic scrotal calcinosis (ISC) is a rare benign condition which presents with multiple, asymptomatic, and painless nodules on the scrotal skin wall [1]. ISC occurs mainly between 20 and 40 years of age. The youngest and the oldest patients were 9 and 85 years old, respectively.

Akosa et al. and, recently, Saad and Zaatari have reported that scrotal calcinosis might result from inflammation of epidermal cysts followed by dystrophic calcification within the keratin of the cyst or dermis adjacent to a ruptured cell wall [2]. Others support the theory of epidermal inclusion cyst playing a major role in the pathogenesis of the disease [3].

Recently, Pabuccuoglu et al. have reported that dartos muscle degeneration and necrosis are the most important factors in the

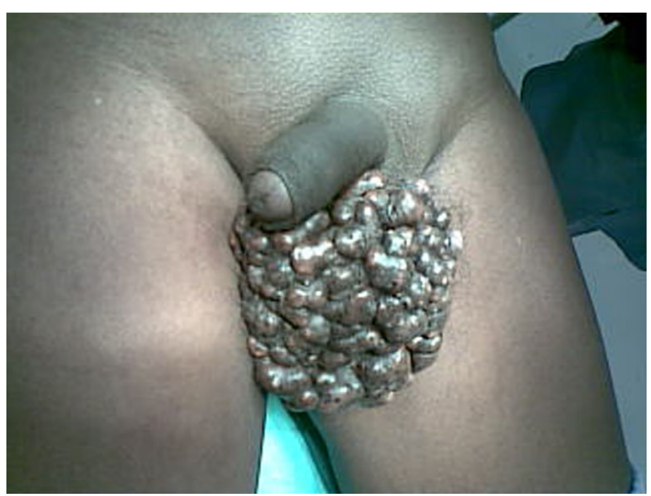

Fig. 1 A 40-year-old male came in surgery OPD for multiple painless nodules involving the whole of the scrotum 


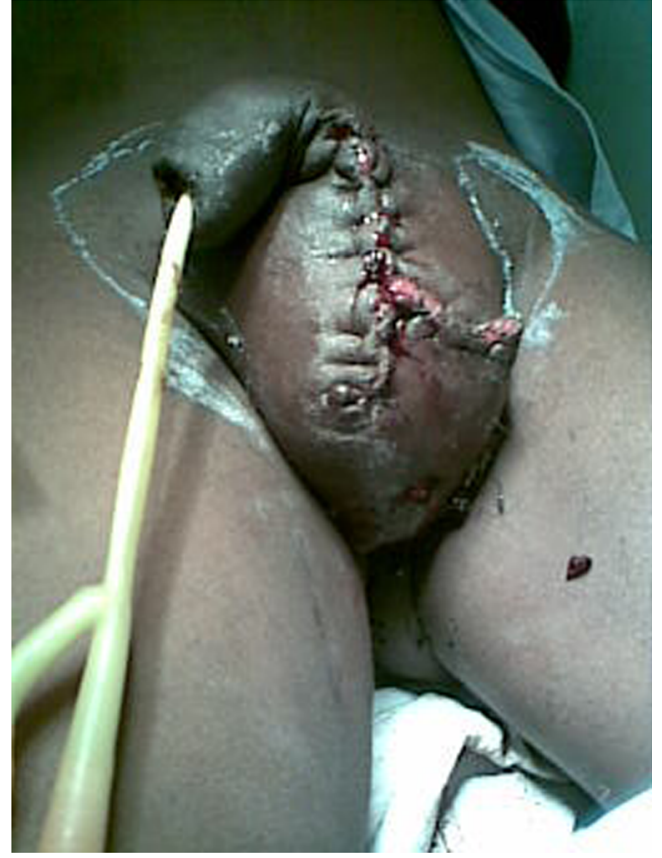

Fig. 2 The patient was posted for in toto excision with skin grafting, but surprisingly, primary closure was possible and his postoperative recovery was very good

process of this pathology [4]. Parlaktaş et al. have suggested that minor trauma plays an important role as the starting point of dystrophic calcification [5].

Histologically, ISC is characterized by the presence of calcium deposits that are variable in size within the dermis, often surrounded by a foreign body-type granulomatous reaction. Some cysts reveal calcification of their keratin contents with little evidence of active inflammation. The lesions have been attributed as sebaceous cysts, calcified steatocystoma, fibroma, atheroma, and xanthoma. Parlaktaş et al. reviewed the histologic data and found no evidence of an epithelial lining, residual cysts, and lipid or organisms and concluded that the calcification was idiopathic introducing the term "idiopathic scrotal calcinosis" [5].

Most of the cases are asymptomatic, and patients usually seek medical advice for cosmetic reasons as in our case. In toto excision is a treatment of choice, but primary closure of

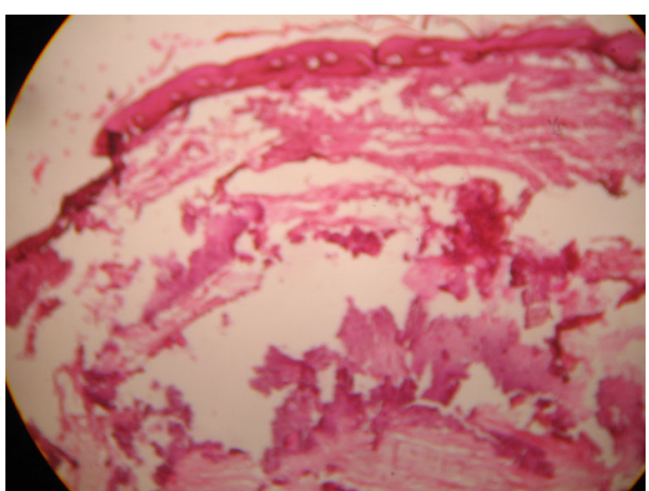

Fig. 3 The specimen was sent for histopathology which was suggestive of calcinosis of the scrotum

the scrotal skin is possible in many of cases as the scrotal skin is very lax.

\section{Compliance with Ethical Standards}

Consent Written informed consent was obtained from patient for publication of images after hiding his identity.

\section{References}

1. Akosa AB, Gilliland EA, Ali MH, Khoo CT (1989) Idiopathic scrotal calcinosis: a possible etiology reaffirmed. Br J Plast Surg 42:324 327

2. Saad AG, Zaatari GS (2001) Scrotal calcinosis: is it idiopathic? Urology 57:365

3. Song DH, Lee KH, Kang WH (1988) Idiopathic calcinosis of the scrotum: histopathologic observations of fifty-one nodules. J Am Acad Dermatol 19:1095-1101

4. Pabuccuoglu U, Canda MS, Guray M, Kefi A, Canda E (2003) The possible role of dartoic muscle degeneration in the pathogenesis of idiopathic scrotal calcinosis. Br J Dermatol 148:827-829

5. Bekir Suha P, Nihat U, Reșit Doğan K, Fikret E, Engin S (2005) Idiopathic scrotal calcinosis: a rare scrotal skin disorder Ankara Üniversitesi. Tip Fak Mecm 58:20-22 